\title{
Identificação e análise de manifestações patológicas em estruturas metálicas dos terminais de ônibus na cidade de Manaus
}

\author{
H. M. MURCHIE. ${ }^{1 *}$, A. R. M. Colares ${ }^{1}$; R. P. VASCONCELOS ${ }^{1}$. \\ *Autor de Contacto: helenammurchie@gmail.com \\ ${ }^{1}$ Departamento de Engenharia Civil, Faculdade de Tecnologia, Universidade Federal do Amazonas, Manaus, Brasil.
}

\begin{abstract}
RESUMO
O presente trabalho teve objetivo de analisar, diagnosticar e indicar possíveis soluções para as manifestações patológicas encontradas nas estruturas metálicas de cinco terminais de ônibus de Manaus. Para tanto, foram realizadas visitas técnicas com registro de informações e imagens que possibilitaram identificar as manifestações mais frequentes. Da análise dos resultados foi possível observar que a corrosão esteve presente em todos os terminais, sendo as corrosões uniforme, em frestas e em torno do cordão de solda as de maior incidência, estando presentes em $100 \%$ dos casos. Essas manifestações patológicas foram classificadas quanto ao grau de risco em cada terminal. Foi feita indicação de tratamento conforme o grau de risco, que variou desde limpeza e proteção química até substituição das peças.
\end{abstract}

Palavras chave: terminais; patologia; metálicas; corrosão; Manaus.

\section{RESUMEN}


El siguiente trabajo tuvo como objetivo analizar, diagnosticar e indicar posibles soluciones a las manifestaciones patológicas encontradas en las estructuras metálicas de cinco terminales de autobuses de Manaus. Para ello, se realizaron visitas técnicas con registro de información e imágenes que permitieron identificar las manifestaciones más frecuentes. Del análisis de los resultados se pudo observar que la corrosión se presentó en todos los terminales, siendo las corrosiones uniformes en las fisuras y alrededor del cordón de soldadura, a las de mayor incidencia, estando presentes en el $100 \%$ de los casos. Estas manifestaciones patológicas se clasificaron según el grado de riesgo en cada terminal. La indicación de tratamiento también fue hecha según el grado de riesgo, que iba desde la limpieza y protección química hasta la sustitución de piezas.

Palabras clave: terminales; patología; metálicas; corrosión; Manaus.

\begin{abstract}
This work intended to analyze, to diagnose and to indicate possible solutions to the pathological manifestations found at metallic structures of five bus terminals at Manaus. For this, technical visits took place, with information and images records that helped to identify the most frequent problems. It was noticed that corrosion was present in all terminals, being uniform, in cracks and by the weld bead the most incident situations, with $100 \%$ occurrence. These pathological manifestations were classified by the degree of risk in each terminal. The treatment indication varied according to the degree of risk, like to clean the pieces, to do chemical protection and to replace some pieces.
\end{abstract}

Keywords: terminals; pathology; metallic; corrosion; Manaus.

\title{
1. INTRODUÇÃO
}

O transporte coletivo urbano tem importância fundamental na qualidade de vida e desenvolvimento de uma metrópole. É responsável pelo deslocamento das pessoas, facilitando a interligação entre as diversas regiões das cidades e incorporando-se aos diferentes segmentos da sociedade, na medida que grande parte da população o utiliza para alcançar seus locais de atividade diárias, permitindo a mobilidade para o trabalho, o acesso à educação, hospitais e lazer, conforme afirmou Ferro (2013). Em Manaus, o transporte coletivo por ônibus se torna ainda mais importante, dada a inexistência de outros meios como metrô ou trem. Nesse sentindo, é essencial que o poder público busque maneiras de alcançar eficiência e qualidade, pois há impacto direto no desenvolvimento econômico local (Jammal, 2010). Ações de manutenção devem ser atividades regulares, de modo a garantir condições mínimas de conforto para os usuários. Neste contexto, deve-se dar atenção à estrutura dos terminais de integração, uma vez que o transporte coletivo em Manaus se dá através de um sistema integrado de transporte caracterizado por um sistema de transbordo tronco alimentado com integração físico-tarifária em terminais fechados, conhecidos como terminais de integração. No total são cinco terminais espalhados pela cidade. Segundo Morlok (1978, apud Souza, 2009), os terminais de integração são alguns dos elementos principais dentro de um sistema de transporte. A estrutura física destes reflete diretamente na qualidade do transporte coletivo. Um bom acompanhamento da situação dos terminais, analisando possíveis patologias construtivas, fazse necessário para assegurar a qualidade dos serviços prestados. Desta forma, o objetivo da pesquisa foi analisar, diagnosticar e indicar soluções para as patologias das estruturas metálicas desses terminais. 


\section{REVISÃO BIBLIOGRÁFICA}

\subsection{O Transporte Coletivo em Manaus.}

A evolução do transporte público está intimamente ligada ao desenvolvimento das cidades. Em Manaus, iniciaram-se diversas obras de infraestrutura, especialmente a pavimentação de ruas, no período do ciclo da borracha, no qual houve a chegada de um grande contingente de pessoas e movimentação da economia. A princípio, foram instalados bondes elétricos que circulavam no perímetro urbano. A partir de 1947, introduziram-se ao transporte coletivo os ônibus de madeira que atendiam regiões que anteriormente não era possível com os bondes (Rodrigues; Oliveira, 2016). Atualmente, o transporte público manauara fundamenta-se em sua frota de ônibus e microônibus. O sistema adotado em dezembro de 2002 é composto por linhas de ônibus que se ligam através da terminais de integração fazendo a conexão entre bairros e o centro (Manaus, 2019). $\mathrm{Na}$ zona sul da cidade situam-se os terminais 1 e 2, na zona norte, os terminais 3 e 6 e na zona leste, os terminais 4 e 5 . O mapa da Figura 1 aponta essa distribuição. Tais terminais são dotados de estruturas de concreto e metálica, sendo o último tipo o escopo do presente trabalho. O terminal 6 não foi objeto de estudo por, à época da pesquisa de campo, ainda não ter sido construído.

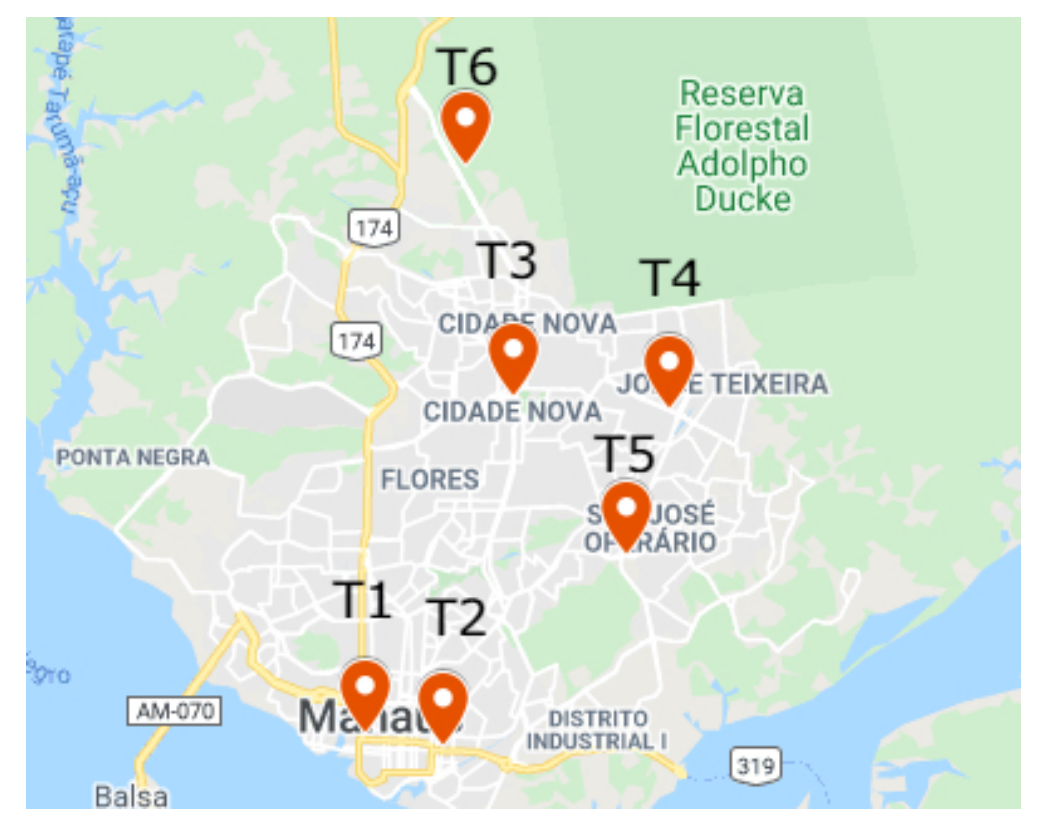

Figura 1 - Distribuição dos terminais de ônibus na cidade de Manaus. Fonte: Google Maps, adaptado pelos autores (2021).

\subsection{Fatores de ocorrência de manifestações patológicas nas estruturas metálicas}

As manifestações patológicas, segundo Castro (1999), são oriundas da atuação de agentes agressivos. Um mesmo agente pode causar efeitos diversos em edificações, o que vai depender do tipo de material empregado e, consequentemente, da resistência da estrutura. No caso das estruturas metálicas, Brinck (2004) classificou as patologias em três categorias: adquiridas, transmitidas e atávicas. A primeira categoria se refere às patologias oriundas da ação de agentes agressivos externos, ou seja, relaciona-se com questões do meio em que está inserido, como por exemplo atmosfera, umidade e vibrações. As patologias transmitidas são originadas pela falta de conhecimento técnico ou vícios construtivos na fase de execução da obra. Por fim, as patologias atávicas resultam de uma má concepção de projeto, diante da escolha de materiais ou até mesmo erros de cálculos. Essas patologias comprometem a segurança e a funcionalidade da estrutura. Outro fator importante é a identificação dos mecanismos de deterioração, que, segundo Bolina et. 
al. (2019), trata-se da identificação do processo promotor da deterioração, seja ele químico, físico, biológico ou mecânico (Tabela 1).

Tabela 1 - Mecanismos de deterioração e formas de ação na estrutura. Fonte: Bolina et. al. (2019, adaptado pelos autores).

\begin{tabular}{|l|l|}
\hline \multicolumn{1}{|c|}{ MECANISMO } & \multicolumn{1}{c|}{ AÇÃO NA ESTRUTURA } \\
\hline Químico & Promove alteração na constituição química do material. \\
\hline Físico & Promove alteração volumétrica através de ação térmica ou higroscópica. \\
\hline Biológico & $\begin{array}{l}\text { Promove mudança ou conversão das propriedades do material base pela } \\
\text { ação de microrganismos. }\end{array}$ \\
\hline Mecânico & $\begin{array}{l}\text { Devidos a esforços externos, dependem da capacidade resistiva do material } \\
\text { e, em geral, culminam em fissuras características. }\end{array}$ \\
\hline
\end{tabular}

O principal fenômeno patológico encontrado nas estruturas metálicas é a corrosão, definida por Callister (2012) como um processo de deterioração de um material devido a reação química ou eletroquímica com o ambiente associada ou não a esforços mecânicos. Normalmente, é um processo espontâneo que produz alterações prejudiciais no material original, inviabilizando sua finalidade pelo prejuízo à durabilidade e, consequentemente, ao desempenho (Liubartas, 2015). A corrosão é, segundo Bolina et. al. (2019), intrínseca aos metais, ocorrendo, por exemplo, durante o processo de fabricação de peças metálicas, dadas as altas temperaturas envolvidas, sendo a corrosão eletroquímica a mais frequente, tendo relação com o estado de tensão e fatores climáticos, como temperatura e umidade. Existe, segundo Rodrigues (2020), uma variedade de formas pela qual a corrosão ocorre, e seu reconhecimento pode ser feito por meio de sua aparência, causa e forma de ataque. Gentil (1999) classifica a corrosão em diferentes tipos, conforme sua morfologia, fatores mecânicos, meio corrosivo, causa ou mecanismo. A mais comum, chamada de corrosão uniforme, é um ataque eletroquímico que ocorre de maneira homogênea por toda superfície do metal que está exposto, ocorrendo perda uniforme de espessura, habitualmente conhecido como ferrugens. Santos (2020) afirma que esse tipo de corrosão é um dos mais fáceis de controlar, ver e proteger pois, em geral, está associado à desproteção do local. Outro tipo de ataque eletroquímico é a corrosão em frestas causada devido ao acúmulo de poeira ou soluções corrosivas em frestas ou reentrâncias como parafusos, porcas, arruelas, juntas rebitadas ou parafusadas. Quando a corrosão origina pequenas cavidades no topo da superfície horizontal do material, ela é conhecida como corrosão tipo pite, causando perda de material, muitas vezes não detectável até a falha. Gasparoni e Rodrigues (2020) afirmam que a corrosão por pite, em geral, é de difícil visualização, dado o pequeno diâmetro e elevada profundidade. A chamada corrosão por placas se localiza na superfície, formando placas com escavações. Já a corrosão por esfoliação se processa de forma paralela à superfície, transfigurando para formas de plaquetas alongadas. O empolamento por hidrogênio é caracterizado pela formação de bolhas, devido a penetração do átomo de hidrogênio no material metálico. A corrosão em torno do cordão de solda, conforme Gasparoni e Rodrigues (2020), ocorre pela formação de pilha galvânica entre os metais da matriz e o metal da solda. Há ainda a corrosão erosão causada pela combinação de um ataque químico e desgaste mecânico.

O meio ambiente também tem grande influência nos processos corrosivos, tendo como um dos fatores causadores principais a ação da atmosfera, que depende da umidade relativa, temperatura e presença de gases, conforme explicou Castro (1999). Maia et. al (2015) afirmam que a chuva é normalmente ácida, sendo um agente agressor que merece especial atenção. Além, disso, Bolina et. al. (2019) atentam para a relação agressividade do meio versus qualidade do material base, sendo essencial para a análise de causalidade das ocorrências de manifestações patológicas e durabilidade das estruturas, pois é o que define o grau de susceptibilidade ao ataque. Carvalho 
(2011) expõe que em uma área de operação de transporte motorizado, como no caso dos terminais de integração de ônibus, há grande emissão de gases poluentes como monóxido de carbono, hidrocarbonetos, óxidos de nitrogênio e enxofre, que quando aliada à elevada umidade relativa do ar, como ocorre na cidade de Manaus, torna suscetível e acelerado o processo de corrosão.

\section{MÉTODOS UTILIZADOS}

Os terminais de integração, como parte essencial da operação de transporte, devem atender as necessidades básicas do usuário, a fim de que exerçam seu direito à cidadania. As edificações devem satisfazer condições mínimas de aspectos de habitabilidade, manutenibilidade e uso, expressas através de parâmetros estabelecidos pela norma técnica, dispondo aos usuários condições de uso, segurança e bem-estar que garantirão a realização de atividades regulares sem que haja interferência do meio em que está inserido (Brinck, 2014). A ocorrência de manifestações patológicas pode significar que o desempenho está insatisfatório, promovendo o encurtamento da vida útil da edificação, caso não ocorra algum tipo de intervenção técnica. Esse envelhecimento precoce compromete aspectos estéticos, socais e econômicos, além de diminuir a capacidade funcional do sistema e colocar em risco a segurança dos usuários (Zuchetti, 2015).

Isto posto, foi realizado levantamento bibliográfico em trabalhos acadêmicos, artigos científicos e materiais didáticos sobre patologias da construção civil, especificamente em estruturas metálicas, com intuito de aprofundamento de conhecimento sobre o tema. Com a disponibilização da documentação dos terminais de integração pela Secretaria Municipal de Infraestrutura de Manaus (Seminf) foi possível fazer uma análise preliminar dos memoriais descritivos, projetos básicos e executivos e relatórios fotográficos dos cinco terminais de integração de ônibus. Como exemplo, a figura 2 mostra o layout do Terminal 2. Além disso, a Seminf deu autorização para pesquisa de campo e disponibilizou acompanhamento as visitas técnicas através de um funcionário. Para o trabalho de campo foi feita a inspeção predial seguindo a Norma de Inspeção Predial Nacional do Instituto Brasileiro de Avaliações e Perícias de Engenharia (IBAPE, 2012). Neste contexto, foi realizada a identificação das anomalias através de análise visual e tátil, mapeamento e registros fotográficos para posterior estudo de causas e efeitos, diagnósticos e listagem das manifestações encontradas para confecção do relatório de causas, caracterização do grau de urgência e sugestão de reparos e medidas preventivas. Para viabilizar o estudo, foram eleitas quatro perguntas norteadoras, postas quando identificada uma anomalia:

1 - Por que ocorre?

2 - Como ocorre?

3 - Qual o nível de gravidade?

4 - Como resolver?

As respostas a esses questionamentos alimentaram os resultados desta pesquisa e o fluxo de trabalho se deu como mostra a figura 3.

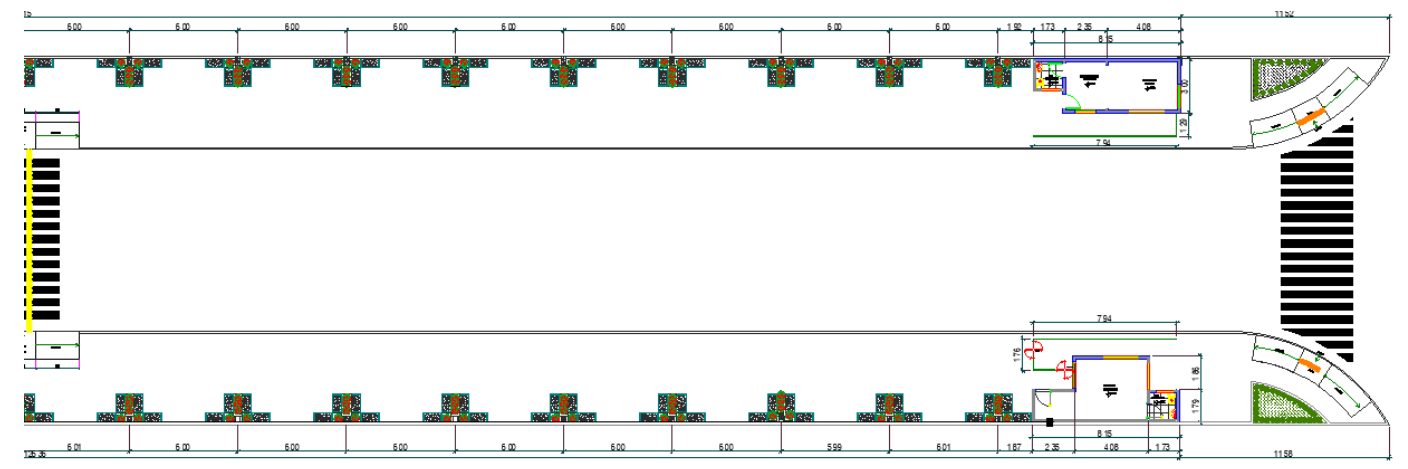

Figura 2 - Layout do Terminal de Integração 2. Fonte: SMTU (2016). 
Levantamento

bibliográfico

Visitas técnicas

Conclusões e

recomendações

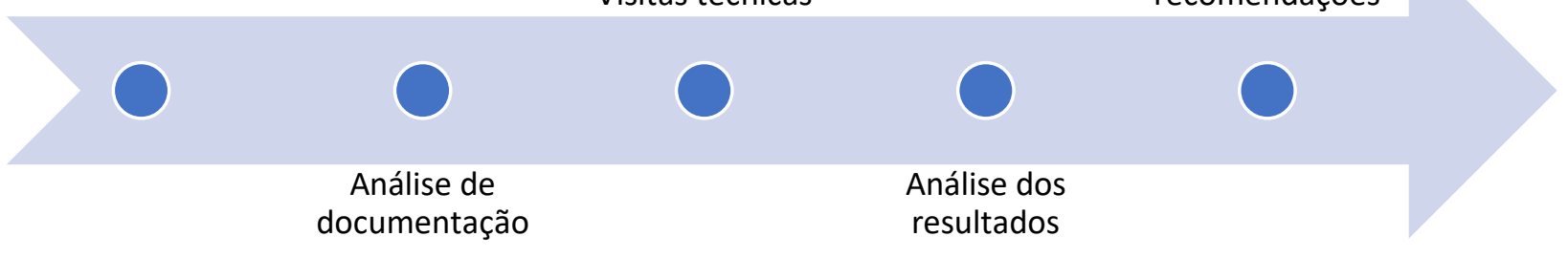

Figura 3 - Fluxo de trabalho seguido.

\section{RESULTADOS E DISCUSSÕES}

Os dados obtidos por meio da pesquisa de campo foram analisados chegando aos resultados contidos na Tabela 2 e Figura 4. Em todos os terminais foram encontradas avarias por choque mecânico, além de corrosão nas estruturas metálicas, diferenciando-se pela morfologia e gravidade da situação. Em relação a morfologia, houve ocorrência de corrosão uniforme, corrosão em frestas e a corrosão em torno do cordão de solda em $100 \%$ dos terminais. A corrosão por esfoliação mostrou-se presente em $80 \%$, já a corrosão por placas e o empolamento por hidrogênio em $60 \%$. A corrosão por pite apresentou-se em apenas $20 \%$ dos casos.

Tabela 2 - Ocorrência das manifestações patológicas por terminal de integração.

\begin{tabular}{|c|c|c|c|c|c|c|c|}
\hline \multirow{2}{*}{$\begin{array}{c}\text { Manifestação } \\
\text { patológica }\end{array}$} & \multicolumn{3}{|c|}{ TERMINAL (ano de construção) } & \multicolumn{2}{c|}{ Ocorrência } \\
\cline { 2 - 8 } & $\begin{array}{c}\text { T1 } \\
\mathbf{( 2 0 0 1 )}\end{array}$ & $\begin{array}{c}\text { T2 } \\
\mathbf{( 2 0 1 6 )}\end{array}$ & $\begin{array}{c}\text { T3 } \\
\mathbf{( 2 0 0 2 )}\end{array}$ & $\begin{array}{c}\text { T4 } \\
\mathbf{( 2 0 0 2})\end{array}$ & $\begin{array}{c}\text { T5 } \\
\mathbf{( 2 0 0 2})\end{array}$ & Absoluta & Percentual \\
\hline Corrosão Uniforme & $\mathrm{x}$ & $\mathrm{x}$ & $\mathrm{x}$ & $\mathrm{x}$ & $\mathrm{x}$ & 5 & $100 \%$ \\
\hline Corrosão por placas & & & $\mathrm{x}$ & $\mathrm{x}$ & $\mathrm{x}$ & 3 & $60 \%$ \\
\hline Corrosão por pites & $\mathrm{x}$ & & & & & 1 & $20 \%$ \\
\hline Corrosão em frestas & $\mathrm{x}$ & $\mathrm{x}$ & $\mathrm{x}$ & $\mathrm{x}$ & $\mathrm{x}$ & 5 & $100 \%$ \\
\hline $\begin{array}{c}\text { Corrosão por } \\
\text { esfoliação }\end{array}$ & $\mathrm{x}$ & & $\mathrm{x}$ & $\mathrm{x}$ & $\mathrm{x}$ & 4 & $80 \%$ \\
\hline $\begin{array}{c}\text { Corrosão em torno } \\
\text { de cordão de solda }\end{array}$ & $\mathrm{x}$ & $\mathrm{x}$ & $\mathrm{x}$ & $\mathrm{x}$ & $\mathrm{x}$ & 5 & $100 \%$ \\
\hline $\begin{array}{c}\text { Empolamento pelo } \\
\text { hidrogênio }\end{array}$ & & & $\mathrm{x}$ & $\mathrm{x}$ & $\mathrm{x}$ & 1 & $60 \%$ \\
\hline Choque Mecânico & $\mathrm{x}$ & $\mathrm{x}$ & $\mathrm{x}$ & $\mathrm{x}$ & $\mathrm{x}$ & 5 & $100 \%$ \\
\hline
\end{tabular}




\section{Ocorrência percentual de manifestações patológicas}

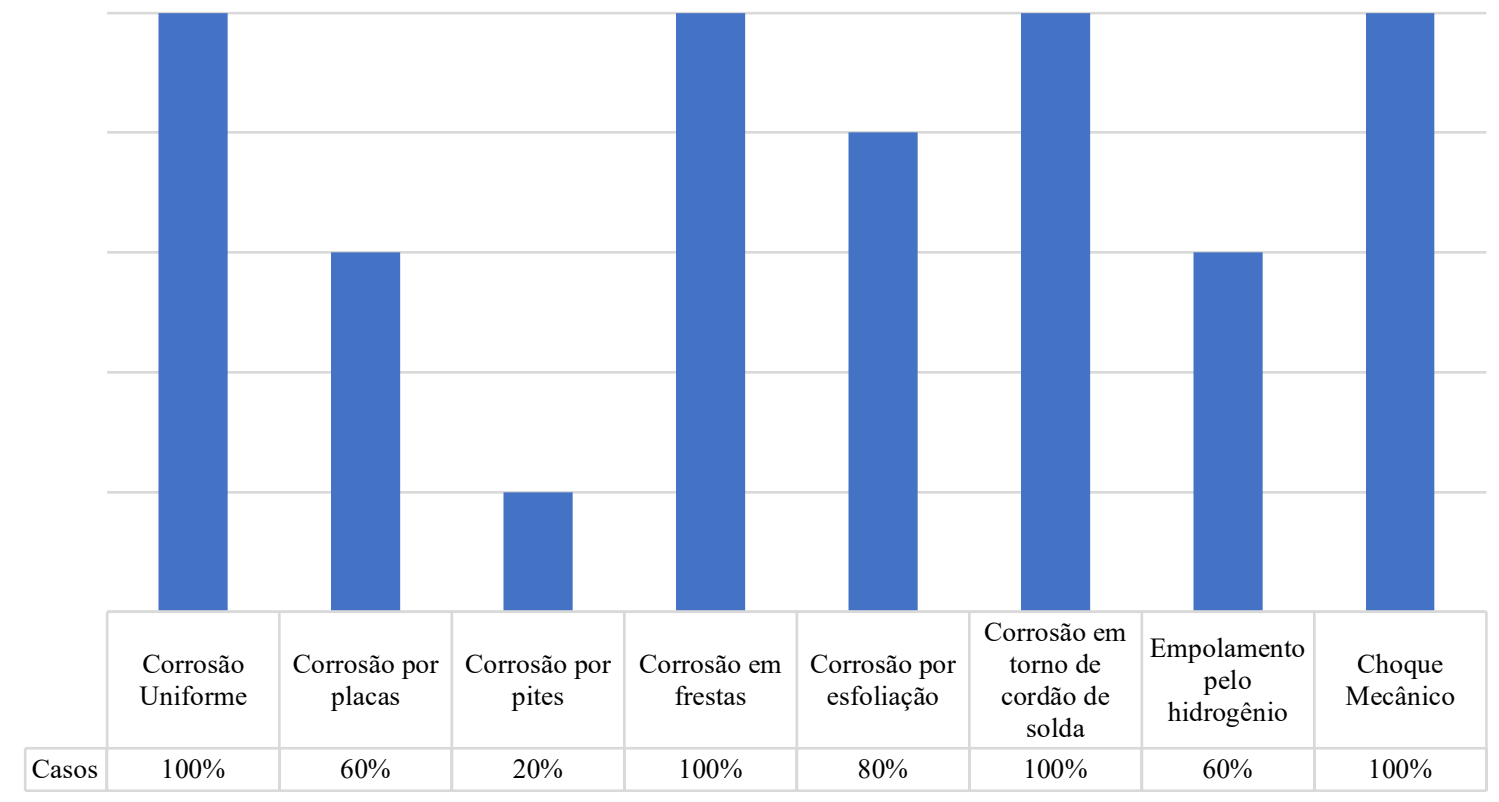

Figura 4 - Ocorrência percentual das manifestações patológicas.

\subsection{Terminal 1}

As plataformas do terminal 1, à época, eram compostas de vigas e pilares metálicos, assim como a estrutura de cobertura, os gradeamentos externos e internos de proteção das escadas dos mezaninos, corrimãos e portões. Nos pilares e vigas foi verificado o início de um processo de oxidação do metal com aparecimento de ferrugem (Figura 5-A). Os pilares, na sua maioria, não apresentavam mais a pintura de proteção e as vigas continham dejetos de pombos (Figura 5-B), o que se pode considerar como agravantes do processo de oxidação encontrado.

$\mathrm{Na}$ cobertura, as terças metálicas não continham qualquer tipo de pintura, sendo constatado uma grande ocorrência de corrosão uniforme por toda extensão do terminal (Figura 5-C). Foi verificado também a existência de danos gerados por choque mecânicos nas telhas, ocasionando pontos de infiltração que intensificam o processo de corrosão. Em relação ao gradeamento externo, os danos encontrados foram ocasionados por choques mecânicos devido a atos de vandalismo e invasão. Já nas grades de proteção das escadas e corrimãos, identificou-se um alto grau de deterioração da estrutura metálica, com perda significativa de material devido ao processo de corrosão em frestas e por esfoliação (Figura 5-D). Essas áreas afetadas continham um grande acúmulo de sujeira e detritos, tornando passível a retenção de umidade. 


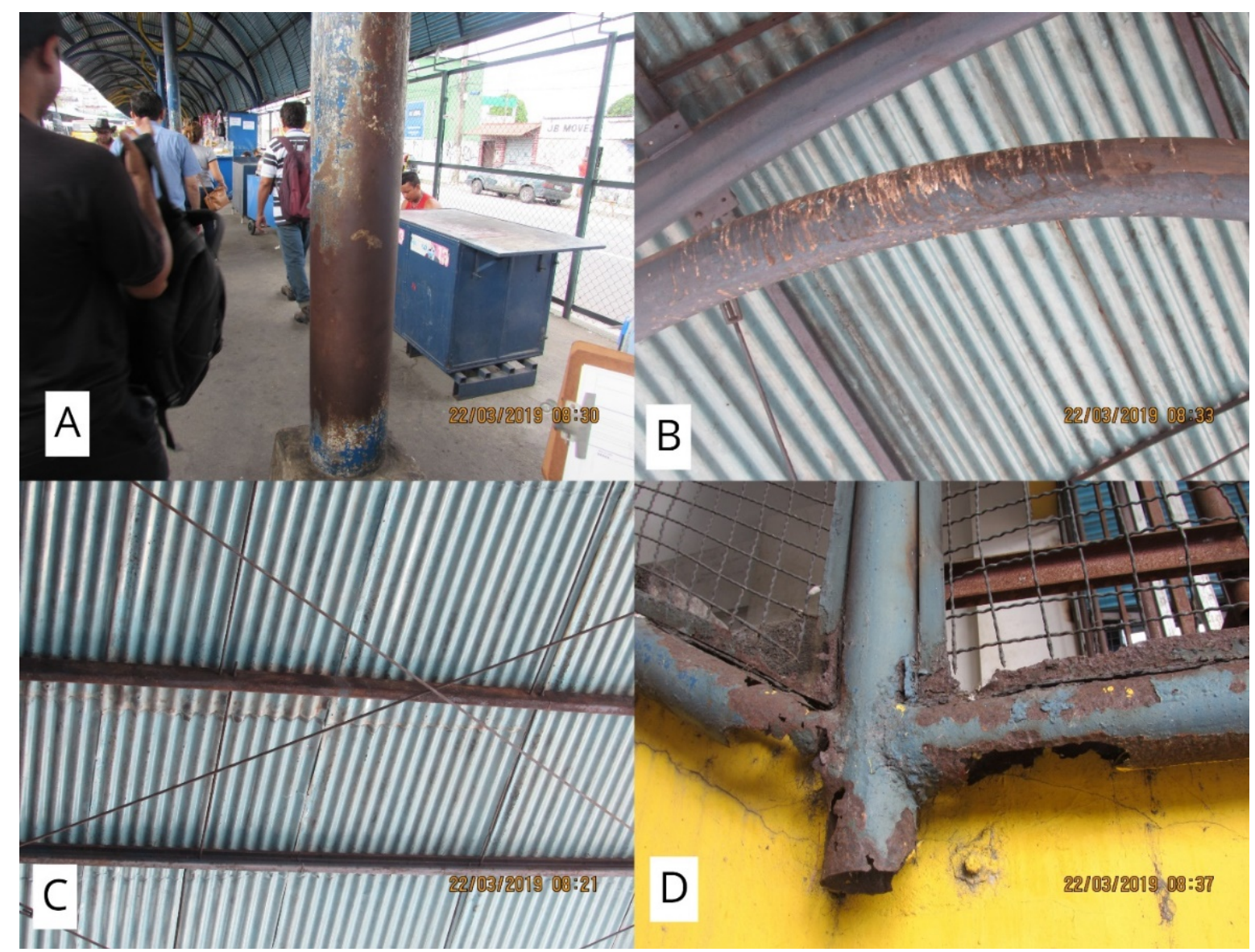

Figura 5 - A: Pilar oxidado; B: Viga contendo dejetos de pombos; C: Corrosão uniforme nas terças da cobertura; D: Corrosão em fresta e por esfoliação com perda de material no gradeamento das escadas.

Nos corrimãos também foi observado ocorrência de corrosão em torno do cordão de solda (Figura 6-A). Os portões do mezanino apresentaram pintura desgastada, com ocorrência de corrosão do tipo uniforme e por pites (Figura 6-B).

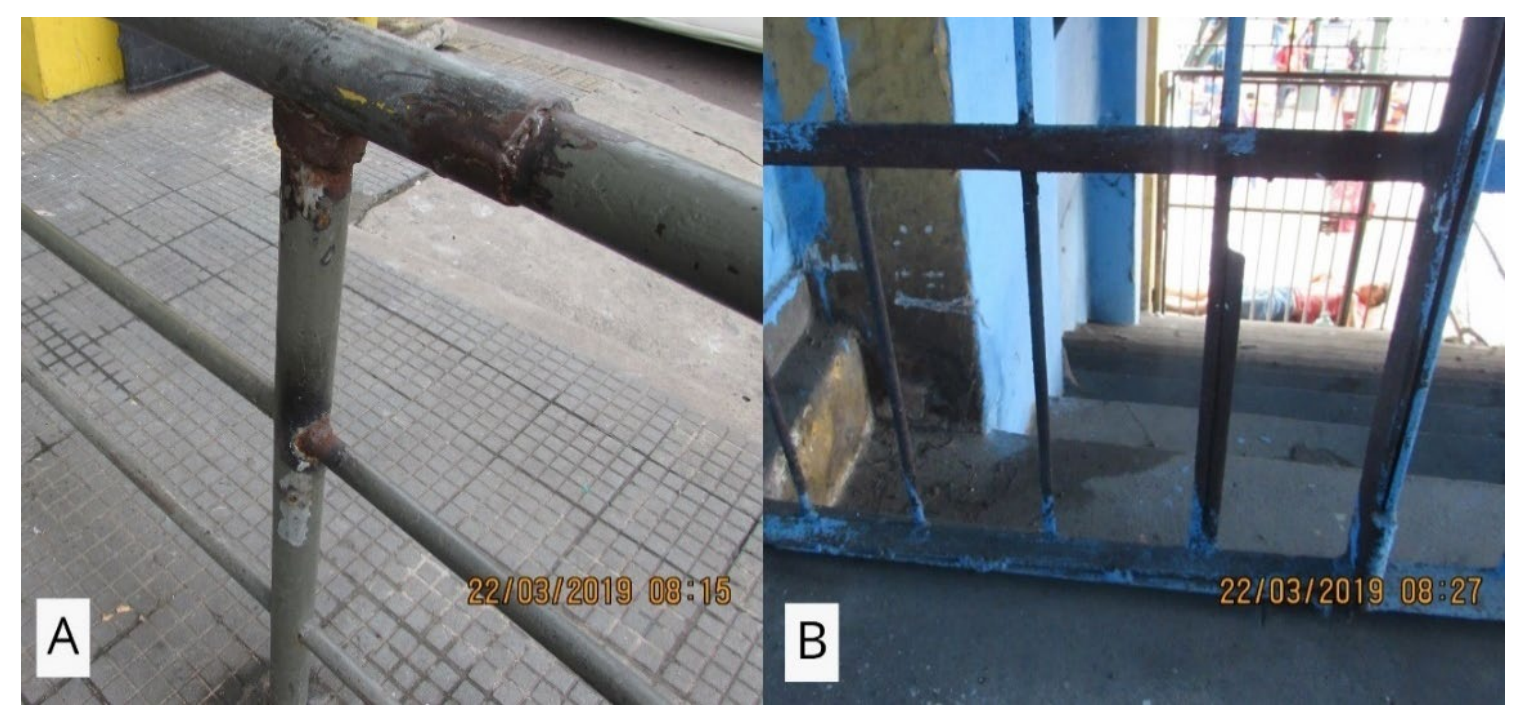

Figura 6 - A: Corrosão em torno do cordão de solda; B: Corrosão por pite nos portões do mezanino 


\subsection{Terminal 2}

O terminal 2, localizada no bairro Cachoeirinha, recebeu uma reforma em 2016, constituindo estruturas metálicas na cobertura e esquadrias. Dentre todos os terminais, as estruturas metálicas do T2 apresentam-se em melhor estado de conservação, contendo pintura em toda sua extensão. Foram observados apenas casos pontuais de corrosão na cobertura, localizadas em ligações de chapa em torno de parafusos (Figura 7-A). Nas esquadrias verificou-se pontos de corrosão uniforme próximo a áreas de infiltrações (Figura 7-B).

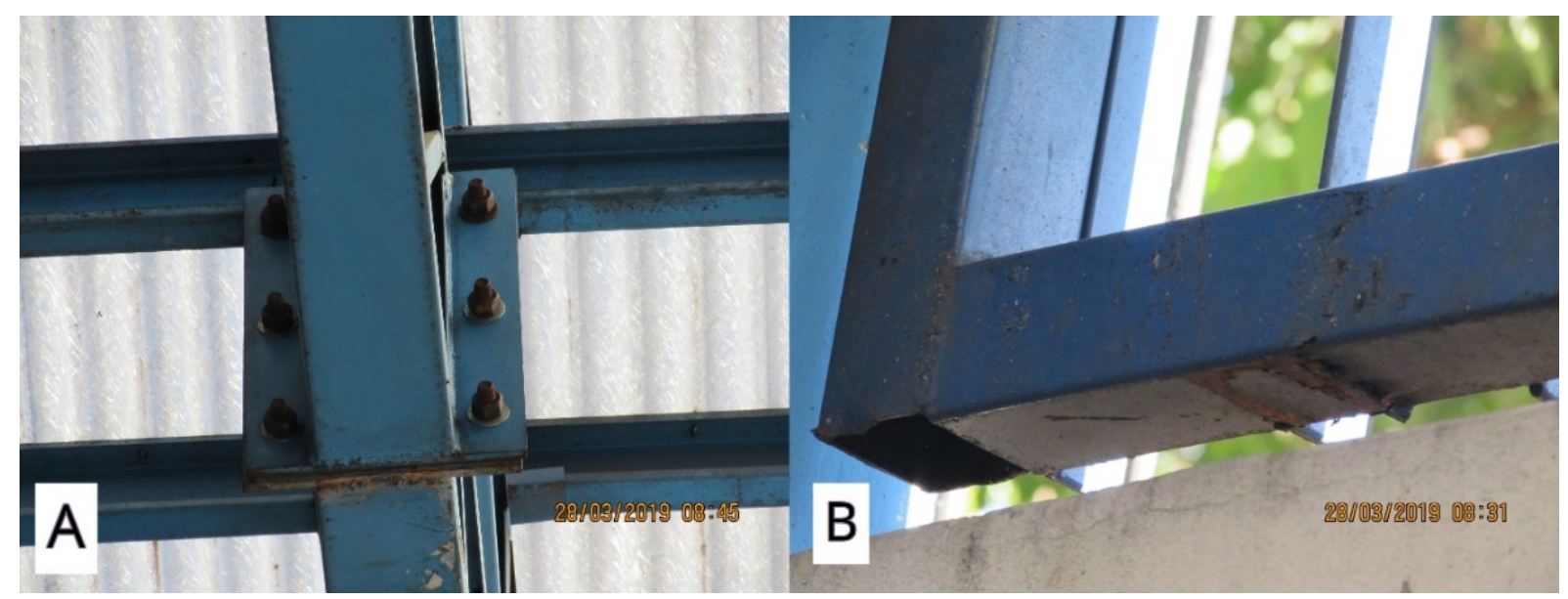

Figura 7 - A: Corrosão em frestas nas ligações de chapa da cobertura; B: Corrosão nas esquadrias.

\subsection{Terminais 3, 4, 5}

Os terminais 3, 4 e 5, localizados nas zonas norte e leste da cidade, possuem o mesmo modelo de projeto arquitetônico e estrutural, composto por estrutura metálica na cobertura, guarda-corpos, escadas, corrimões e tubulações pluviais. Foram constatados nos terminais pontos de infiltração de água devido a danos por choque mecânico e desgaste químico, por conta da ação atmosférica, nas telhas e calhas dos sistemas de coberturas. As treliças espaciais tinham pintura, porém com sinais de desgaste na sua maioria (Figura 8-A). Os tipos de corrosão uniforme e em frestas foram as com maior ocorrência nessas estruturas, agravadas pelo acúmulo de poeira, dejetos de pombo e pontos de infiltração. Em alguns casos, como no T3, observou-se a perda de material (Figura 8-B). Nos guarda-corpos e corrimões foi observado desgaste da pintura, com presença de oxidação e ferrugem, além de empolamento por hidrogênio (Figura 8-D). Em locais de grande circulação de pessoas, além de oxidação, também foi encontrado fissuras nos corrimãos metálicos. Possivelmente, o atrito entre as mãos dos usuários e os corrimãos gera um processo de desgaste na estrutura que favorece o mecanismo da corrosão, levando a fenômenos em cadeia de oxidação, perda de resistência e, por fim, aparecimento de fissura e fendas (Figura 8-C). Assim como corrimões, as tubulações apresentaram-se com corrosão, na maioria dos casos, uniforme. 


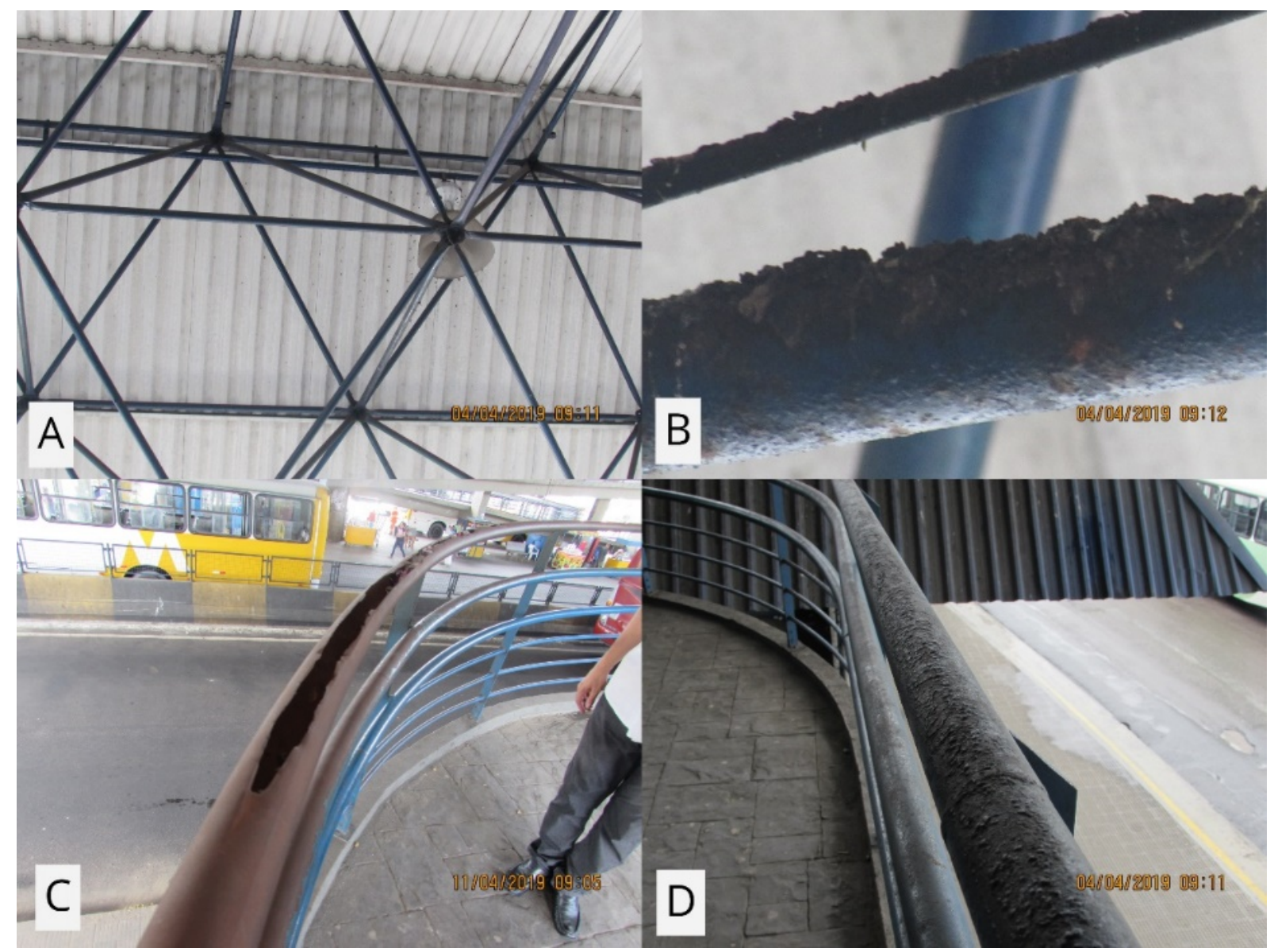

Figura 8 - A: Estrutura da cobertura dos terminais; B: Perda de material devido a corrosão na cobertura do T3; C: Corrimões oxidados com fendas no T4; D: Empolamento por hidrogênio no T4.

Os piores casos de deterioração do material devido a corrosão foram encontrados na base dos pilares metálicos das escadas dos terminais. Nestes locais, a corrosão ocorre, principalmente, por meio de esfoliação e por placas. Há uma grande perda de material, e, em alguns casos, total perda da função estrutural (Figura 9).

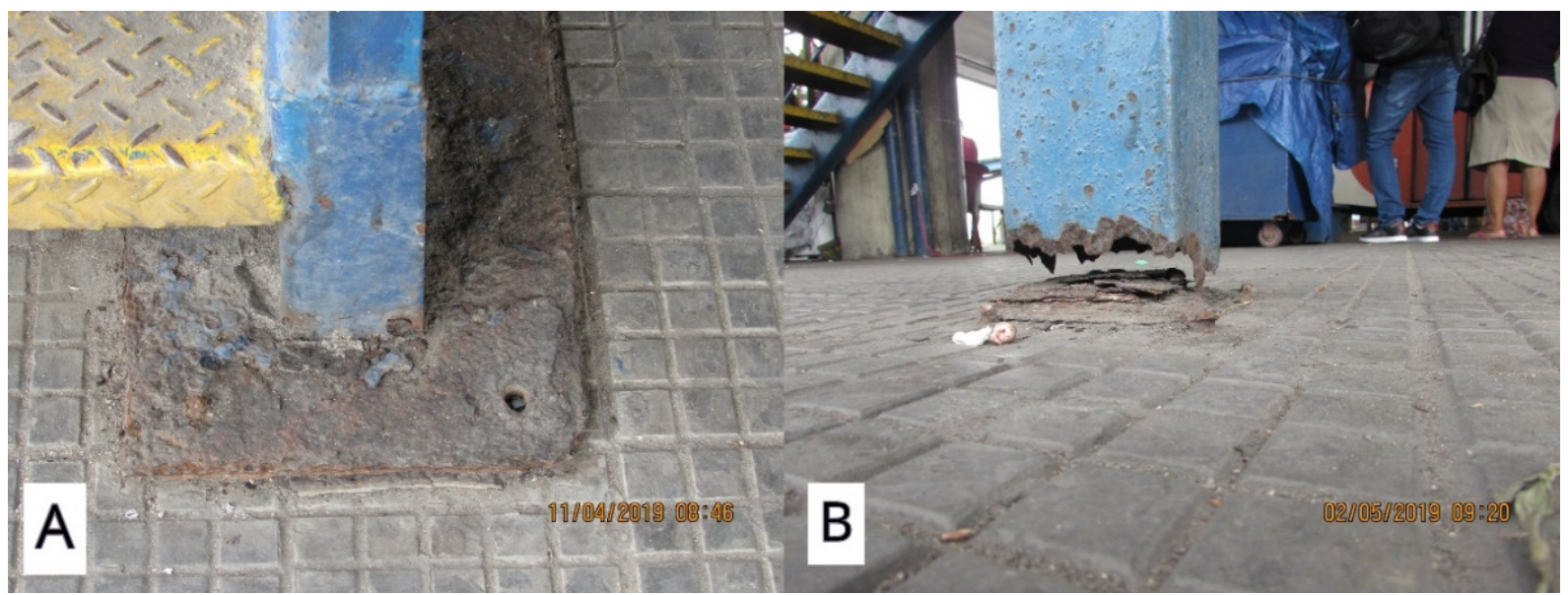

Figura 9 - A: Corrosão em placa e por esfoliação no pilar metálico da escada do T5; B: Perda de material no pilar da escada. 


\section{4 - Classificação das manifestações quanto ao grau de risco}

Segundo a Norma de Inspeção Predial Nacional (IBAPE, 2012), as anomalias podem ser classificadas quanto ao grau de risco oferecido aos usuários, ao meio ambiente e ao patrimônio. Quando ocorre risco de provocar danos à saúde e segurança das pessoas e do meio ambiente, tendo perda do desempenho e funcionalidade classificamos como crítico (1). Quando ocorre risco de provocar perdas parciais de desempenho e funcionalidade sem prejuízo direto ao sistema classificamos como médio (2). E quando ocorre risco de provocar pequenos prejuízos relacionados a estética sem comprometer a funcionalidade da edificação classificamos como mínimo (3). A Tabela 3 denota a classificação em relação ao grau de risco das manifestações patológicas encontradas nos terminais de integração.

Tabela 3 - Classificação das manifestações patológicas quanto ao grau de risco.

\begin{tabular}{|c|c|c|c|c|c|}
\hline Manifestação Patológica & T1 & T2 & T3 & T4 & T5 \\
\hline Corrosão Uniforme & 2 & 3 & 2 & 2 & 2 \\
\hline Corrosão por placas & & & 1 & 1 & 1 \\
\hline Corrosão por pites & 2 & & & & \\
\hline Corrosão em frestas & 1 & 3 & 1 & 1 & 1 \\
\hline Corrosão por esfoliação & 1 & & 1 & 1 & 1 \\
\hline Corrosão em torno de cordão de solda & 3 & 3 & 2 & 2 & 2 \\
\hline Empolamento pelo hidrogênio & & & 3 & 3 & 3 \\
\hline Choque Mecânico & 2 & 2 & 2 & 2 & 2 \\
\hline
\end{tabular}

De modo geral, o terminal 1 apresentou grau de risco de mediano a crítico, sendo encontrado casos que expunham os usuários a risco de acidentes com possibilidade de contaminação, prejudicando sua saúde e segurança. O terminal 2 classificou-se como grau de risco mínimo, sendo baixas as ameaças de danos a edificação. A similaridade dos terminais 3, 4 e 5, tanto em relação a layout e sistemas estruturais como em idade, leva-os a apresentar problemas semelhantes com grau de risco de mediano a crítico, uma vez que foram encontrados casos que podem causar perda da função estrutural e, consequentemente, prejuízo ao sistema e à segurança dos usuários. Como solução de reparo dos elementos que apresentaram manifestações de corrosão com grau de risco mínimo e mediano, como é o caso das estruturas de cobertura dos terminais, se recomendou realização de limpeza dos elementos corroídos com jato de areia ao metal quase branco, padrão visual 2\%, aplicando em seguida um primer anticorrosivo e uma pintura inibidora e preventiva de novos processos corrosivos. A utilização de pistola de pintura é importante, visando a obtenção de camadas espessas da película protetora. Já para os elementos que apresentaram um grau de risco crítico, na qual a corrosão danificou a peça estruturalmente, propôs-se substituição parcial ou total do elemento, a depender da extensão do dano, sendo necessário que o novo elemento receba também tratamento preventivo, garantindo segurança ao sistema estrutural. A questão dos custos para os reparos não foi avaliada por se entender que estava fora do escopo da pesquisa. Além disso, deve-se destacar que é fundamental também que haja planos de manutenção, para garantir a atualização das condições funcionais das estruturas, para que se possa programar intervenções de conservação antecipadamente, isto é, que haja programação para retoque anual da pintura, limpeza, e garantia das condições de utilização dos elementos metálicos. 


\section{CONCLUSÃO}

A funcionalidade do transporte coletivo está intimamente associada aos elementos que compõem o sistema, como é o caso dos terminais de integração de ônibus. Assim, a presença de manifestações patológicas nas estruturas metálicas desses terminais pode causar danos à ergonomia e desempenho desses serviços, assim como põe em risco a segurança dos usuários. A deterioração do metal, por meio do processo de corrosão, foi verificada em todos os terminais, com formas diversas de manifestação. Em casos mais severos, gerou preocupação quanto à segurança estrutural e funcionalidade da edificação devido à redução significativa de material. As principais manifestações patológicas encontradas foram a corrosão uniforme, a corrosão em frestas, corrosão em torno do cordão de solda e o choque mecânico, seguidas da corrosão por esfoliação e por placas. As maiores ocorrências dessas manifestações foram observadas na parte das coberturas, que apresentavam grande acúmulo de poeira, advinda das partículas geradas pela queima de combustíveis fósseis dos ônibus, dejetos de pássaros e pontos de infiltração que favorecem a umidade. Deve-se levar em consideração também a acidez da água das chuvas que, no médio e longo prazo, contribuem para o agravamento do problema. Além disso, notou-se anomalias em elementos não-estruturais como guarda-corpos e corrimãos, principalmente onde havia acúmulo de lixo. Os choques mecânicos foram verificados no gradeamento externo, telhas e guarda-corpos entre plataformas, provocados por atos de vandalismo e colisão dos ônibus. Os elementos afetados pelas manifestações patológicas passam a impressão visual de estarem em fím de vida útil, causando sensação de insegurança nos usuários e funcionários dos terminais. Tais elementos quando sofrem corrosão podem tomar formato cortante, com perigo agravado pela presença de óxido de ferro e umidade, que favorecem a proliferação de bactérias locais. Além disso, a perda de material causa a perda da função estrutural. Por esses motivos, a maioria dos terminais, com exceção do terminal 2, foram classificados com um grau de risco mediano à crítico, sendo seus elementos passíveis de tratamentos para recuperação através de limpeza com jatos de areia e aplicação de primer e pintura inibidora, com especificações adequadas às características dos problemas. Essa diferença do T2 para os outros quatro pode ser associada ao fato de ser o de menor idade, tendo sido exposto a agentes agressivos por tempo inferior aos demais, que foram construídos entre 2001 e 2002. Apesar disso, a realização de manutenção preventiva é importante para todos os terminais, a fim de que se possa evitar ou reduzir as falhas, assegurando a segurança e o desempenho da edificação durante sua vida útil.

Os resultados da pesquisa foram entregues à Secretaria Municipal de Infraestrutura em junho de 2019. Em outubro do mesmo ano, como atividade obrigatória do Programa Institucional de Bolsas de Iniciação Científica e sem publicação de resumo ou artigo em anais, o relatório final foi apresentado no Congresso de Iniciação Científica (XXVIII CONIC-UFAM), evento da Universidade Federal do Amazonas. Em 2020 ocorreram mudanças significativas no sistema de transporte urbano de Manaus, como a reconstrução do T1, entregue em 17 de maio de 2021, construção do T6 e intervenções de conservação nos demais terminais.

\section{AGRADECIMENTOS}

Os autores agradecem à Secretaria Municipal de Infraestrutura de Manaus pelo apoio prestado durante as visitas técnicas e consulta aos projetos, também à Fundação de Amparo à Pesquisa do Estado do Amazonas e ao Conselho Nacional de Desenvolvimento Científico e Tecnológico pela concessão de bolsas, e à Universidade Federal do Amazonas pelo incentivo às atividades de pesquisa por meio do Programa Institucional de Bolsas de Iniciação Científica. 


\section{REFERÊNCIAS}

BOLINA, F. L. et. al. (2019), "Patologia de estruturas". Oficina de Textos, São Paulo: SP.

BRINCK, F. M. (2004), "Efeito da Corrosão na Integridade Estrutural da Ponte Metálica Marechal Hermes”. 2004. 227 f. Dissertação (Mestrado) - Curso de Engenharia Civil, Departamento de Engenharia Civil da Escola de Minas, Universidade Federal de Ouro Preto, Ouro Preto: MG. Disponível em: $<\mathrm{http} / / /$ www.repositorio.ufop.br/bitstream/123456789/6637/3/DISSERTA\%C3\%87\%C3\%83O_ EfeitoCorros\%C3\%A3oIntegridade.pdf $>$. Acesso em: 02 set. 2018.

CALliSTER, W. D; RETHWISCH, D. G. (2012), "Ciência e Engenharia de Materiais: Uma Introdução". 8. ed. LTC, Rio de Janeiro: RJ.

CASTRO, E. M. C. (1999), "Patologia dos Edifícios em Estrutura Metálica”. 204 f. Dissertação (Mestrado) - Curso de Engenharia Civil, Departamento de Engenharia Civil da Escola de Minas, Universidade Federal de Ouro Preto, Ouro Preto: MG. Disponível em: $<$ http://livros01.livrosgratis.com.br/cp104704.pdf>. Acesso em: 02 set. 2018.

CARVAlHO, C. H. R. (2011), "Emissão Relativas de Poluentes de Transportes Motorizados de Passageiros nos Centros Urbanos Brasileiros". Ipea, Brasília: DF. Disponível em: $<$ http://www.ipea.gov.br/portal/images/stories/PDFs/TDs/td_1606.pdf > . Acesso em: 6 out. 2018

FERRO, S. R. O. P. B; FONSECA, V. (2013), "Transporte Público Urbano: Condições dos Terminais de Integração da Região Metropolitana de Aracaju/SE”. In: Interfaces Científicas: Direito, v. 1, n. 2, p.9-17, Aracaju: SE. Mensal. Disponível em: $<$ https://periodicos.set.edu.br/index.php/direito/article/download/310/221>. Acesso em: 6 ago. 2021.

GASPARONI, A. G.; RODRIGUES, L. M. (2020), “Corrosão de estruturas metálicas em águas $e$ sua proteção". RFB Editora, Belém: PA. Disponível em: $<$ https://deposita.ibict.br/bitstream/deposita/210/2/CORROS\%c3\%83O\%20DE\%20ESTRUTUR AS\%20MET\%c3\%81LICAS.pdf>. Acesso em 04 de ago. 2021.

GENTIL, V. (1996), “Corrosão”. 3. ed. LTC, Rio de Janeiro: RJ.

GOOGLE Maps (2021), "Mapa da cidade de Manaus". Disponível em: <maps.google.com>. Acesso em 31 mai. de 2021.

INSTITUTO Brasileiro de Avaliações e Perícias de Engenharia (2012), "Norma De Inspeção Predial Nacional". Ibape, São Paulo: SP. Disponível em: <http://ibapenacional.com.br/biblioteca/wp-content/uploads/2012/12/Norma-de-Inspe\%C3\%A7\%C3\%A3oPredial-IBAPE-Nacional.pdf>. Acesso em: 13 fev. 2019.

JAMMAL, M. F. (2010), “Análise dos Requisitos de Qualidade do Transporte Coletivo Urbano de São José do Rio Preto - SP - Usando o Método QFD”. 103 f. Dissertação (Mestrado) - Curso de Engenharia Urbana, Universidade Federal de São Carlos, São Carlos: SP. Disponível em: $<$ https://repositorio.ufscar.br/bitstream/handle/ufscar/4299/3508.pdf? sequence=1\&isAllowed=y $>$ . Acesso em: 2 set. 2018. 
LIUBARTAS, D. et al. (2015). “A sustentabilidade do aço e das estruturas metálicas". Inovae, v. 3, n. 1, p.92-110, São Paulo: SP. Quadrimestral. Disponível em: $<$ http://revistaseletronicas.fmu.br/index.php/inovae/article/view/382>. Acesso em: 07 ago. 2021.

MAIA, D. J. et al. (2015). “Experimento sobre a influência do pH na corrosão do ferro". Química Nova na Escola, v. 37, n. 1, p.71-75, São Paulo: SP. Trimestral. Disponível em: $<$ http://qnesc.sbq.org.br/online/qnesc37_1/11-EEQ-69-13.pdf>. Acesso em: 07 ago. 2021.

MANAUS. Prefeitura de Manaus. Instituto Municipal de Mobilidade Urbana (2019), "Terminais de Integração”. Disponível em: <http://transporte.manaus.am.gov.br/terminais-de-integracao/>. Acesso em: 2 set. 2019.

RODRIGUES, P. R. S.; OLIVEIRA, V. M. (2016), “Transporte Coletivo Por Ônibus Em Manaus: Análise Das Linhas No Contexto Norte-Sul". Manaus: AM. Disponível em: $<$ https://www.webartigos.com/artigos/transporte-coletivo-por-onibus-em-manaus/146516>. Acesso em: 4 out. 2018.

SANTOS, M. R. (2020), "Manual de uso, operação e manutenção de edificações em estruturas metálicas”. 95 f. Monografia (Graduação) - Curso de Engenharia Civil, Instituto Federal de Educação, Ciência e Tecnologia de Sergipe, Aracaju: SE. Disponível em: < https://repositorio.ifs.edu.br/biblioteca/bitstream/123456789/1481/1/Maria\%20Rita\%20dos\%20S antos.pdf>. Acesso em: 04 ago. 2021.

SOUZA, M. H. (2009), "Contribuição metodológica para localizar terminal de integração de passageiros do transporte hidro-rodoviário urbano”. 238 f. Tese (Doutorado) - Curso de Engenharia de Transportes, Coppe, Universidade Federal do Rio de Janeiro: RJ. Disponível em: $<$ http://www.pet.coppe.ufrj.br/index.php/pt/producao/teses-de-dsc/doc_download/155contribuicao-metodologica-para-localizar-terminal-de-integracao-de-passageiros-do-transportehidro-r>. Acesso em: 12 ago. 2018.

SUPERINTENDÊNCIA Municipal de Transportes Urbanos (2016), "Planta Baixa - Terminal 2". Prefeitura de Manaus, Manaus: AM.

ZUCHETTI, P. A. B. (2015), "Patologias Da Construção Civil: Investigação Patológica Em Edifício Corporativo De Administração Pública No Vale Do Taquari/RS”. 128 f. TCC (Graduação) - Curso de Engenharia Civil, Centro Universitário Univates, Lajeado: RS. Disponível em:

$<$ https://www.univates.br/bdu/bitstream/10737/939/1/2015PedroAugustoBastianiZuchetti.pdf $>$. $\begin{array}{llll}\text { Acesso } & \text { em: } & 26 & \text { nov. }\end{array}$ 